\title{
Teleneurology Expansion in Response to the COVID-19 Outbreak at a Tertiary Health System in New York City
}

Benjamin R. Kummer, MD, Chloe Sweetnam, MSc, Barbara G. Vickrey, MD, MPH, Georges Naasan, MD, Dayneen Harvey, CPC, Kimberly Gallagher, and Nathalie Jetté, MD, MSc

Neurology: Clinical Practice April 2021 vol. 11 no. 2 e102-e111 doi:10.1212/CPJ.0000000000001057
Correspondence

Dr. Kummer

benjamin.kummer@mountsinai.org

\section{Abstract \\ Objective}

To assess the implementation of teleneurology (TN), including patient and clinician experiences, during the coronavirus respiratory disease 2019 (COVID-19) pandemic.

\section{Methods}

We studied synchronous (video visit) and asynchronous (store-andforward, patient-portal evaluation, remote monitoring) TN utilization in the Mount Sinai Health System Neurology Department in New York, 2 months before and after the start of our department's response to the pandemic in mid-March 2020. Weekly division meetings enabled ongoing assessments and analysis of barriers and facilitators according to the Consolidated Framework for Implementation Research and the Expert Recommendations for Implementing Change models. We used postvisit surveys of clinicians

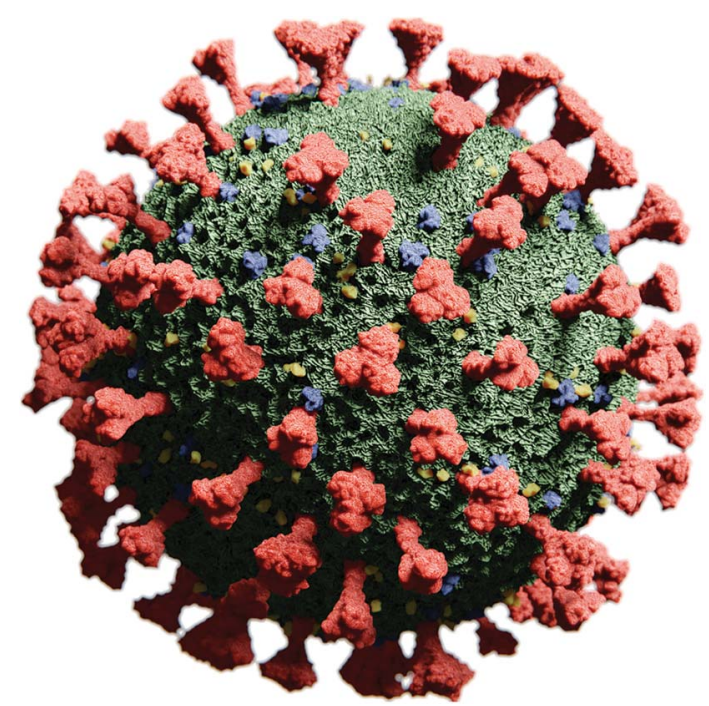
(from April 13 to May 15, 2020) and patients (from May 11 to 15, 2020) to determine technology platforms used, and TN experience and acceptability, using Likert scales $(1=$ very poor/unlikely to 5 = very good/likely).

\section{Results}

Over the 4-month period, $117 \mathrm{TN}$ clinicians ( $\mathrm{n}=14$ subspecialties) conducted 4,225 TN visits with 3,717 patients (52 pre- vs 4,173 post-COVID-19). No asynchronous TN services were delivered. Post-COVID-19, the number of TN clinicians, subspecialties performing TN, and visits increased by $963 \%, 133 \%$, and 7,925\%, respectively. Mean acceptability among patients and clinicians was 4.7 (SD 0.6) and 3.4 (SD 1.6), respectively. Most video visits were completed using Epic MyChart (78.5\%) and Zoom (8.1\%). TN implementation facilitators included Medicare geographic restriction waivers, development of clinician educational materials, and MyChart outreach programs for patients experiencing technical difficulties.

\section{Conclusions}

A significant expansion of TN utilization accompanied the COVID-19 response. Patients found TN more acceptable than did clinicians. Proactive application of an implementation framework facilitated rapid and effective TN expansion.

\section{MORE ONLINE}

\section{COVID-19 Resources}

For the latest articles, invited commentaries, and blogs from physicians around the world NPub.org/COVID19

Department of Neurology (BRK), Icahn School of Medicine at Mount Sinai and Clinical Informatics, Mount Sinai Health System; Department of Neurology (CS, BV, GN, DH, KG) and Departments of Neurology and Population Health Science and Policy (NJ), Icahn School of Medicine at Mount Sinai, New York.

Funding information and disclosures are provided at the end of the article. Full disclosure form information provided by the authors is available with the full text of this article at Neurology.org/cp. 
Teleneurology (TN) is the application of telemedicine to neurology. ${ }^{1-3}$ TN comprises many services, including realtime (synchronous) audio-only or audio-video evaluations, nonsimultaneous (asynchronous) electronic communications between clinicians and patients, or review of recorded digital imaging or physiologic monitoring data. ${ }^{4}$ Synchronous TN in particular has been used for several decades, ${ }^{5}$ while TN, according to its broader definition, has been the focus of multiple recent studies. ${ }^{6,7}$

The outbreak of coronavirus respiratory disease 2019 (COVID-19) that occurred in Wuhan, China, in December 2019 has evolved into a global pandemic. By late June 2020, more than 12 million cases of COVID-19 were reported worldwide, of which over 3 million were in the United States. As early as March 27th, 2020, New York City (NYC) emerged as the national center of the COVID-19 pandemic in the United States, ${ }^{8}$ growing to over 390,000 confirmed cases and 30,000 deaths as of late July $2020 .^{9}$

As a result of shelter-in-place orders in multiple US states, which were intended to limit virus transmission, ${ }^{10}$ in-person visits to ambulatory practices significantly decreased across the country. ${ }^{11}$ However, by allowing virtual interactions between patients and clinicians, telemedicine has also enabled many neurologic patients to maintain access to care during the pandemic. Furthermore, multiple state and federal policy reforms increased reimbursement, loosened geographic restrictions, and relaxed licensing requirements for telemedicine in the United States during the pandemic, resulting in significant telemedicine expansion., 32,13

Although reports of pandemic-related TN expansion exist, ${ }^{14}$ information is lacking on patient and clinician experience, as well as the breadth and comparative advantages of available TN technology platforms. In this study, we sought to describe TN expansion in a tertiary care neurology department in NYC, highlighting clinician and patient experiences, available technology platforms, and the barriers encountered during TN implementation using a formal implementation framework.

\section{Methods}

\section{Study Design and Population}

We conducted a mixed-methods study of TN implementation and experience using qualitative and quantitative data from patients and clinicians in the Department of Neurology at the Icahn School of Medicine at Mount Sinai (ISMMS) in NYC. ISMMS is the medical school of the Mount Sinai Health System (MSHS), an academic hospital system comprised of 7 separate medical campuses across NYC. We defined TN as synchronous audio-video evaluation or asynchronous care service between neurologic clinicians and patients. In defining asynchronous $\mathrm{TN}$, we included clinician-patient interactions over patient portals and review of recorded image or remote physiologic device data. We excluded interprofessional electronic consultations, which comprised only $1.1 \%$ of all $\mathrm{TN}$ in an internal analysis of TN visits (data not shown), due in part to the deployment of the majority of referring clinicians to COVID medicine teams or to other deployment services in the face of the pandemic.

The study population was defined as all outpatients in the department's faculty practice at 5 locations around our health system (The Mount Sinai Hospital, Mount Sinai Beth Israel, Mount Sinai West, Mount Sinai Morningside, and Mount Sinai Brooklyn) who had received at least $1 \mathrm{TN}$ visit between January 16, 2020, and May 15, 2020. Patients from the institution's hospital-based outpatient clinics, which are separate from faculty practice clinics, were excluded. We divided the 4-month study interval into prepandemic and pandemic periods, designating March 16, 2020, as the date coinciding with the initiation of expansion of synchronous TN training to all neurology faculty, in response to the COVID pandemic. All visits, patients, and services were identified using our institutional Epic (Epic Systems Corporation, Verona, WI) electronic health record (EHR).

\section{Standard Protocol Approvals, Registrations, and Patient Consents}

The Mount Sinai Hospital IRB approved the use of patient clinical data and clinician experience information for this study under protocol number 20-03341 and waived the requirement for informed consent.

\section{TN Before the COVID-19 Pandemic}

Before the COVID-19 outbreak, TN visits had already been conducted in the Department of Neurology using VSee Messenger (VSee, Sunnyvale, CA), a desktop and mobile device-based platform, as well as a mobile Epic solution leveraging Vidyo videoconferencing technology (Vidyo, Hackensack, NJ). The Epic solution consisted of a clinicianfacing mobile device EHR application (Epic Haiku or Canto) and a patient-facing, mobile portal application (Epic MyChart). Although both patient and clinician-facing applications were available for mobile telephones and tablets, desktop installations for the Epic solution were not supported due to excessively complex information technology requirements. Although VSee Messenger was EHR agnostic, the Epic Haiku/Canto platform could only be used with Apple iOS devices such as iPhone or iPad (Apple Inc., Cupertino, CA). Despite VSee being vendor agnostic, the Epic platform offered superior integration with the institutional EHR and therefore was adopted by the Department as the official platform for a rolling TN pilot program, which began on May 1,2019 , with 2 faculty members who served as early adopters.

The TN pilot program was originally planned and executed before the COVID-19 pandemic by an implementation team in the Department of Neurology that included a clinical informaticist (B.K.), an implementation scientist (C.S.), a medical coding specialist (D.H.), an outpatient 
administrative director (K.G.), and departmental administrative leadership (G.N. and B.V.). Two team members (C.S. and B.K.) recruited faculty clinicians into the program by regularly conducting demonstrations of the MyChart platform to faculty in face-to-face subspecialty meetings. Interested faculty contacted the team by email, were trained by dedicated information technology staff with expertise in Epic MyChart, and had their Epic accounts configured to schedule TN visits in Epic.

Because of the strict limitations on insurance coverage and geographic location in the pre-COVID-19 era, a proactive process was developed to determine patients' eligibility and suitability for TN. As part of this process, the team's implementation scientist met with each registering clinician to screen their schedule in advance to identify suitable patients for TN. Suitability was determined based on the patient's insurance coverage, geographic location, and assessment of technological literacy. Telemedicine educational material, including details on New York and several other states' telemedicine regulations, as well as policies pertaining to billing and coding, clinician and patient location restrictions for Medicare-insured patients, and guidance on documentation of the remote neurologic examination, was made available to all registering clinicians.

\section{TN During the Pandemic}

In response to the federally declared state of emergency on March 13, 2020, ${ }^{15}$ and growing questions and requests from patients during the first 2 weeks of March 2020, our department began rapidly expanding training to use MyChart for synchronous TN to all Neurology faculty, starting March 16,2020 . Patients were contacted ahead of their upcoming appointments and given the option to either receive care through a telephone visit or TN video visit or to defer care to a later date. During this period, face-to-face encounters between patients and providers were not allowed except in urgent situations that might avoid an emergency department (ED) visit, due to public health concerns. However, departmental leadership did not specifically mandate that TN be used exclusively.

A New York State-wide shelter-in-place order was issued on March 20, 2020. ${ }^{10}$ The implementation team collected feedback and data on ongoing implementation barriers and facilitators from clinician and administrator stakeholders in weekly division (subspecialty) meetings held by teleconference with screen sharing. Between March 23 and April 13, the same group used stakeholder feedback to develop a best practices guide for conducting and billing synchronous $\mathrm{TN}$ visits, which was comprised of sections on telemedicine state laws and reimbursement policies, remote neurologic examination guidance, a step-by-step instructional how to bill for a TN visit, and frequently asked questions. This guide was electronically disseminated to stakeholders and regularly updated.

In addition, the Office of Civil Rights of the US Department of Health and Human Services announced on March 30, 2020, that it would temporarily limit its enforcement of Health Insurance Portability and Accountability Act (HIPAA) compliance for technology platforms used to conduct telemedicine. In effect, this policy change allowed neurologists to use both HIPAA- and non-HIPAA-compliant platforms to conduct TN. Although our implementation workgroup consistently promoted the MyChart platform as the HIPAA-compliant, EHRintegrated, and therefore preferred platform of Mount Sinai to the faculty clinicians, the same workgroup also communicated to faculty clinicians the temporary enforcement limitation and its implications. Furthermore, to minimize impediments to care delivery during the COVID-19 crisis, departmental leadership did not impose sanctions or other limitations on clinician platform choices, and clinicians were free to choose whichever platform they desired to conduct the TN encounter. ${ }^{16}$

Starting April 13, an anonymous electronic experience survey (appendix e-1, links.lww.com/CPJ/A265) was sent daily to all TN clinicians to further ascertain challenges that were commonly reported by clinicians in regular stakeholder meetings. The survey asked clinicians to rate their experience with the day's synchronous TN visits, report whether a switch from the MyChart platform was necessary to complete the majority of $\mathrm{TN}$ visits, list which alternative platform was chosen if a switch was necessary, and why a switch of platform was required. The survey also assessed the quality of the audio and video for the majority of that day's synchronous TN visits on a 5-point Likert scale ${ }^{17}$ ranging from 1 (very poor) to 5 (very good), as well as the likelihood of recommending synchronous $\mathrm{TN}$ to a colleague on a similar scale ranging from 1 (very unlikely) to 5 (very likely).

As part of an institutional patient experience initiative, an anonymous electronic postvisit experience survey was sent to all patients who had a synchronous telemedicine visit from May 1, 2020, onward (appendix e-2, links.lww.com/CPJ/ A266). The survey was adapted from a general telemedicinefocused Press Ganey experience instrument and incorporated custom survey items based on input from MSHS leadership. The survey assessed patient experience with telemedicine across multiple areas, including ease of accessing the visit, discussing care with clinicians, using TN technology, and the likelihood of recommending TN to a friend or family member. All items were rated on a 5-point Likert scale ranging from 1 (very poor/unlikely) to 5 (very good/likely). We focused on experience with TN by only analyzing surveys returned by patients evaluated in neurology faculty practices.

\section{Measurements}

From the EHR, we collected patient age, preferred sex, race, and primary insurance. We identified synchronous TN visits by using internal Epic telemedicine visit codes, and asynchronous TN visits (excluding e-consults) by using Current Procedure Terminology service codes for store-and-forward review of recorded images or video (G2010), digital evaluation and management services (99421-3), and remote physiologic monitoring services (99453-4). We categorized 
each faculty member into neurologic subspecialties by their assigned divisions. We counted total TN visits, TN clinicians, clinician subspecialties, and normalized visit counts according to business day, clinician, and subspecialty.

We calculated mean Likert scale ratings for survey responses. We used the reported likelihood of recommending TN as a metric for patient and clinician acceptability. For clinicians, we additionally calculated the proportion of visits requiring a switch from the MyChart platform, which we then stratified according to reason categories. Because clinician experience may evolve after initial implementation, we compared these measurements from surveys completed soon after clinician survey administration began (April 20-24, 2020) and at the end of the study period (May 11-15, 2020). We used implementation- and progress-focused formative evaluation to understand emerging barriers to $\mathrm{TN}$ implementation and continuously revise our implementation approach based on feedback to fit the site's context during a time of rapid change in our health system. ${ }^{18}$ Implementation barriers and facilitators were documented in detail by the team's implementation scientist (C.S.) at monthly debriefing meetings before the pandemic and weekly meetings during the pandemic as TN volume increased.

Notes from these meetings were cleaned, organized by subspecialty, and analyzed using a hybrid inductive-deductive approach, with deductive codes informed by the Consolidated Framework for Implementation Research, ${ }^{19}$ and inductive codes derived from emerging themes in formative evaluation data. Findings were discussed during weekly implementation team meetings, and the implementation strategy was tailored to fit the site's context, in accordance with the Expert Recommendations for Implementing Change model. ${ }^{20}$

\section{Statistical Analysis}

We used descriptive statistics to summarize patient-level and visit-level data. We used the Student $t$ test and Wilcoxon rank-sum test to compare continuous variables and the $\chi^{2}$ or Fisher exact test to compare categorical variables, respectively, between study periods. Statistical significance was set to $p<0.05$. All statistical analyses were performed in $\mathrm{R}$ version 3.5.3 ( $\mathrm{R}$ Foundation for Statistical Computing, Vienna, Austria).

\section{Data Availability}

Deidentified and/or anonymized data may be made available on request by qualified investigators with sponsorship by an institution. IRB determination/approval will be required.

\section{Results}

\section{TN Visits and Patients}

Over the 4-month study period, we identified $117 \mathrm{TN}$ clinicians, who performed 4,225 unique TN visits with 3,717 patients across 14 subspecialty practices and 6 technology platforms. No asynchronous TN services were identified during the study period. Between periods, total clinicians conducting TN visits increased by $963 \%$, the number of subspecialties providing TN services increased by $133 \%$, and the total number of TN visits increased by $7,925 \%$. The majority of visits, occurring in the early stages of the COVID19 pandemic, were for established patients (69.9\%), although the proportion of new patients evaluated by $\mathrm{TN}$ increased by $250 \%$ during the pandemic (table 1). Of the patients evaluated by TN during the entire period, mean age was 48.8 years (SD 19.9), and 2,251 (60.6\%) were female. Comparing patients from both periods, patients evaluated during the pandemic were significantly older overall, and comprised significantly higher proportions of non-White patients, as well as patients aged younger than 18 years and older than 66 years. Insurance coverage and sex were not significantly different between periods (table 2).

\section{Patient and Clinician Experience}

The total number of patients responding to the postvisit survey was 208 , representing $5 \%$ of synchronous TN visits occurring during the pandemic. Because the patient survey had no required fields, some questions were missing responses. However, the lowest number of respondents for a given question was 204 ( $<2 \%$ missing data). The mean overall acceptability score for TN (range of $1=$ lowest to $5=$ highest) was 4.7 (SD 0.6), with the lowest individual experience rating being 4.4 (SD 1.0) for the ease of logging into the TN visit, followed by 4.5 (SD 0.8) for the clarity of visit login instructions (table 3 ).

Between April 13 and May 15, 2020, we sent 804 surveys to TN clinicians, who supplied 351 (43.6\%) survey responses in relation to 1,139 completed visits. The most frequent platform used to complete a TN visit was Epic MyChart (894 visits; $78.5 \%$ ), followed by Zoom (92; 8.1\%). Of the completed visits, 92 (8.3\%) required a switch from MyChart to a non-MyChart platform. The most frequent reasons cited for switching to a non-MyChart platform were nonspecific technical difficulty experienced with MyChart (25 visits; $29.4 \%$ ), followed by network connection failures (14; $16.5 \%)$. In cases where a platform switch was required, Apple FaceTime $^{\mathrm{TM}}$ (42; 49.4\%) was the most frequently chosen non-MyChart platform. On a 5-point Likert scale, audio and video quality was rated 4.1 (SD 1.0) and TN acceptability 3.4 (SD 1.6) (table 4). In comparing clinician experience surveys soon after implementation to those from the end of the study, the only significant difference was an increase in the mean Likert score for recommending $\mathrm{TN}$ to a colleague (3.4 vs $4.1, p=0.04$ ).

\section{Ongoing Implementation Evaluation}

Several barriers to adoption were identified through thematic analysis of formative evaluation data during the TN implementation (table e-1, links.lww.com/CPJ/A263). These included challenges in adapting platforms to meet the needs of patients and clinicians, administrative 
Table 1 TN Utilization Characteristics, Stratified by Study Period

\begin{tabular}{|c|c|c|c|}
\hline Characteristic & $\begin{array}{l}\text { Pre- } \\
\text { COVID-19 } \\
(\mathrm{N}=52)\end{array}$ & $\begin{array}{l}\text { During } \\
\text { COVID-19 } \\
(\mathrm{N}=4,173)\end{array}$ & $\begin{array}{l}p \text { Value } \\
\left(\chi^{2} \text { or }\right. \\
\text { Wilcoxon } \\
\text { rank-sum) }\end{array}$ \\
\hline No. of clinicians conducting TN & 11 & 117 & \\
\hline No. of platforms used for TN & 2 & 6 & \\
\hline No. of established patient visits & $47(90.4)$ & $2,916(69.9)$ & $<0.01$ \\
\hline \multicolumn{4}{|l|}{ No. of asynchronous TN visits } \\
\hline Remote monitoring & $0(0.0)$ & $0(0.0)$ & 1.0 \\
\hline $\begin{array}{l}\text { Store-and-forward image/video } \\
\text { review }\end{array}$ & $0(0.0)$ & $0(0.0)$ & 1.0 \\
\hline $\begin{array}{l}\text { Patient portal evaluation and } \\
\text { management }\end{array}$ & $0(0.0)$ & $0(0.0)$ & 1.0 \\
\hline No. of subspecialties offering TN & 6 & 14 & \\
\hline $\begin{array}{l}\text { No. of visits per business day, } \\
\text { median (IQR) }\end{array}$ & $2.0(1.7)$ & $87.0(61.0)$ & $<0.01$ \\
\hline $\begin{array}{l}\text { No. of visits per clinician, } \\
\text { median (IQR) }\end{array}$ & $3.0(4.5)$ & $21.0(43.0)$ & $<0.01$ \\
\hline $\begin{array}{l}\text { No. of visits per subspecialty, } \\
\text { median (IQR) }\end{array}$ & $8.5(10.5)$ & $\begin{array}{l}235.0 \\
(456.0)\end{array}$ & $<0.01$ \\
\hline $\begin{array}{l}\text { No. of visits per individual } \\
\text { subspecialty }\end{array}$ & & & $<0.01$ \\
\hline Cognitive neurology & $0(0.0)$ & $140(3.3)$ & \\
\hline Epilepsy & $7(13.5)$ & $380(9.1)$ & \\
\hline General neurology & $0(0.0)$ & $727(17.4)$ & \\
\hline Headache & $19(36.5)$ & $596(14.3)$ & \\
\hline Movement disorders & $1(1.9)$ & $600(14.4)$ & \\
\hline Neuro-immunology & $10(19.2)$ & $650(15.6)$ & \\
\hline Neuro-oncology & $0(0.0)$ & $68(1.6)$ & \\
\hline Neuro-ophthalmology & $0(0.0)$ & $15(0.4)$ & \\
\hline Neuro-otology & $0(0.0)$ & $33(0.8)$ & \\
\hline Neuromuscular disease & $0(0.0)$ & $190(4.5)$ & \\
\hline Neuropsychology & $14(26.9)$ & $301(7.2)$ & \\
\hline Palliative neurology & $0(0.0)$ & $3(0.1)$ & \\
\hline Pediatric neurology & $1(1.9)$ & $241(5.8)$ & \\
\hline Stroke & $0(0.0)$ & $229(5.5)$ & \\
\hline
\end{tabular}

Abbreviations: COVID-19 = coronavirus disease 2019; IQR = interquartile range; $\mathrm{TN}=$ teleneurology.

Data are reported as N (\%), unless otherwise noted.

challenges in registration and scheduling due to frequently changing policies in the setting of the COVID-19 pandemic, inherent limitations of the remote neurologic examination such as the fundoscopic, reflex, and sensory examinations, technological failures precluding the completion of TN visits, lack of patient feedback soon after the start of the COVID-19 TN response, and interstate practice
Table 2 Characteristics of Patients Evaluated by TN Before and During the COVID-19 Response, Stratified by Study Period

\begin{tabular}{|c|c|c|c|}
\hline Characteristic & $\begin{array}{l}\text { Pre-COVID-19 } \\
(\mathrm{N}=44)\end{array}$ & $\begin{array}{l}\text { During COVID-19 } \\
(\mathrm{N}=3,673)\end{array}$ & $\begin{array}{l}p \\
\text { Value } \\
\text { ( } \chi^{2} \text { or } \\
t \text { test) }\end{array}$ \\
\hline Age, mean (SD), y & $43.3(14.8)$ & $48.8(20.0)$ & 0.02 \\
\hline Age category & & & $<0.01$ \\
\hline $0-17$ y & $0(0.0)$ & $218(5.9)$ & \\
\hline $18-65 y$ & $41(93.2)$ & $2,568(69.9)$ & \\
\hline 66 y or older & $3(6.8)$ & $887(24.1)$ & \\
\hline Female sex & $31(70.4)$ & $2,220(60.4)$ & 0.21 \\
\hline Race & & & 0.03 \\
\hline American Indian & $0(0.0)$ & $9(0.2)$ & \\
\hline Asian & $0(0.0)$ & $115(3.1)$ & \\
\hline Black & $0(0.0)$ & $434(11.8)$ & \\
\hline Pacific Islander & $0(0.0)$ & $21(0.6)$ & \\
\hline Unknown & $12(27.3)$ & $1,265(34.4)$ & \\
\hline White & $32(72.7)$ & $1,829(49.8)$ & \\
\hline $\begin{array}{l}\text { Primary insurance } \\
\text { coverage }\end{array}$ & & & 0.75 \\
\hline Association/union & $0(0.0)$ & $81(2.2)$ & \\
\hline Commercial & $27(61.4)$ & $1,958(53.3)$ & \\
\hline Medicaid & $3(6.8)$ & $315(8.6)$ & \\
\hline Medicare & $9(20.4)$ & $997(27.1)$ & \\
\hline Self-pay & $1(2.3)$ & $93(2.5)$ & \\
\hline Unknown & $4(9.1)$ & $211(5.7)$ & \\
\hline Workers' compensation & $0(0.0)$ & $18(0.5)$ & \\
\hline
\end{tabular}

Abbreviations: COVID-19 =coronavirus respiratory disease 2019; $\mathrm{TN}=$ teleneurology.

Figures are reported as N (\%), unless otherwise noted.

restrictions. These were respectively addressed by training administrative staff to provide guidance to patients by telephone on activating the MyChart patient portal and checking into $\mathrm{TN}$ visits, identifying clinician and administrative champions to promote $\mathrm{TN}$ adoption and staff education, creating a best practices guide on optimally performing the remote neurologic examination that was disseminated to clinician stakeholders, and frequently updating providers and schedulers on temporary licenses and licensing waivers in place. Barriers were also addressed by creating a guide to telephone-based evaluation of patients as a backup in the case of technological failures and engaging health system leadership to create a scalable, telemedicine-focused patient experience survey across multiple ambulatory specialties. 
Table 3 Patient Experience With Synchronous TN During the COVID-19 Pandemic

\begin{tabular}{lll}
\hline Experience domain & $\begin{array}{l}\text { 5-Point } \\
\text { likert } \\
\text { score }\end{array}$ & $\begin{array}{l}\text { Respondent, } \\
\mathrm{N}\end{array}$ \\
\hline Visit access & & \\
\hline Ease of contacting clinic & $4.6(0.7)$ & 204 \\
\hline Ease of arranging appointment & $4.6(0.9)$ & 208 \\
\hline Clarity of visit login instructions & $4.5(0.8)$ & 206 \\
\hline Overall access experience rating & $4.6(0.7)$ & 208 \\
\hline
\end{tabular}

Visit care clinician

\begin{tabular}{lll}
\hline $\begin{array}{l}\text { Degree of concern shown for questions } \\
\text { or worries }\end{array}$ & $4.9(0.4)$ & 207 \\
\hline $\begin{array}{l}\text { Discussion of proposed treatments } \\
\text { (risks/benefits, etc.) }\end{array}$ & $4.9(0.5)$ & 206 \\
\hline $\begin{array}{l}\text { Efforts to include patient in care } \\
\text { decisions }\end{array}$ & $4.9(0.5)$ & 206 \\
\hline Ability to explain problems/conditions & $4.9(0.5)$ & 207 \\
\hline $\begin{array}{l}\text { Likelihood of recommending visit care } \\
\text { clinician to others }\end{array}$ & $4.9(0.5)$ & 204 \\
\hline Overall care clinician experience rating & $4.9(0.5)$ & 207 \\
\hline
\end{tabular}

\section{Visit technology}

\begin{tabular}{lll}
\hline Ease of logging into video visit & $4.4(1.0)$ & 207 \\
\hline $\begin{array}{l}\text { Ease of talking with care clinician over } \\
\text { video }\end{array}$ & $4.6(0.9)$ & 208 \\
\hline Quality of audio connection during visit & $4.5(1.1)$ & 207 \\
\hline Quality of video connection during visit & $4.5(1.0)$ & 205 \\
\hline Overall technology experience rating & $4.5(0.8)$ & 208
\end{tabular}

\section{General experience}

\begin{tabular}{lll}
\hline $\begin{array}{c}\text { How well clinical team worked } \\
\text { together to care for patient }\end{array}$ & $4.8(0.6)$ & 205 \\
\hline $\begin{array}{l}\text { Likelihood of recommending } \\
\text { TN to others }\end{array}$ & $4.7(0.8)$ & 204 \\
\hline Overall experience rating & $4.7(0.6)$ & 206 \\
\hline
\end{tabular}

Abbreviations: COVID-19 = coronavirus respiratory disease 2019; TN = teleneurology.

All patient experience data are included from dates May 1, 2020, to May 15, 2020.

All data reported as mean (SD) unless otherwise noted.

${ }^{a}$ All Likert scores are rated on scales ranging from 1 (very poor/unlikely) to 5 (very good/likely).

\section{Discussion}

We found significant increases in synchronous TN visits, clinicians, subspecialties, and technology platforms in response to the COVID-19 crisis in a large academic health system in NYC. We found that patients generally reported high acceptability with synchronous TN, whereas clinicians reported numerically lower acceptability. Although we also found that MyChart logistics were the most significant reason for switching platforms, MyChart remained the most frequently used platform to complete synchronous TN visits, likely because of MyChart's position as MSHS' primary telemedicine platform. The barriers to adoption that we identified involved lack of adaptability and malfunctions in technology platforms, administrative burdens due to frequently changing workflows, and inherent limitations of the remote neurologic examination, as well as the fact that several dozen of our neurology faculty and administrators were deployed to COVID medicine or other teams during May and part of June 2020, thereby limiting their availability to provide TN care during this period. State-wide and federal practice policy shifts that loosened restrictions on licensure and telemedicine reimbursement, and proactive ongoing small group meetings to obtain data on barriers and facilitators, as well as disseminate practice guidelines, helped increase successful expansion.

We found that patients and clinicians experienced MyChart logistical challenges with synchronous $\mathrm{TN}$, which resulted in switching to non-MyChart platforms. These challenges included problems logging into the mobile application, electronically checking into the visit, and audio or video malfunctions. We also found that patients reported the least satisfaction with visit check-ins, which are consistent with the challenges reported in the clinician survey. Despite these logistical challenges, we observed that patients found TN more acceptable overall than did clinicians. It remains unclear whether this may have been related to the logistical impact of technical difficulties on the remainder of a clinician's workday or the effect of technological literacy. Although patients reported higher audio and video quality than clinicians, rapid increases in platform usage, which occurred across multiple medical specialties during the pandemic response, may have also contributed to audio and video interruptions.

Of interest, although the audio and video quality and rate of MyChart visits requiring a platform switch did not increase between April and May 2020, provider acceptability did significantly improve during this time frame, which suggests that at least some of the reported dissatisfaction with TN may have been related to the initial troubleshooting and problems that frequently accompany the implementation of any technological system. The evaluation period was admittedly limited to only 2 months, so we cannot definitively conclude whether the technical dimensions of provider experience improved as providers became more accustomed to TN workflows.

Patients reported high acceptability (4.7 of 5 ) as defined by likelihood of recommending TN to others, whereas the numerical rating of providers regarding the likelihood of recommending TN to colleagues ( 3.4 of 5) was more than a full point lower on the same 5-point Likert scale, although that rating improved to a mean of 4.1 over the course of the study period. Technology issues were reported as a challenge some of the time by providers. It is also possible that provider and 
Table 4 Clinician Experience With Synchronous TN During the COVID-19 Pandemic

\begin{tabular}{|c|c|}
\hline Surveys sent, $\mathbf{N}$ & 804 \\
\hline Survey responses received & $\begin{array}{l}351 \\
(43.6)\end{array}$ \\
\hline Audio/video connection rating, mean (SD), Likert scale ${ }^{a}$ & $4.1(1.0)$ \\
\hline Likelihood of recommending TN to a colleague, mean (SD), Likert scale ${ }^{b}$ & $3.4(1.6)$ \\
\hline No. of visits completed by respondents & 1,139 \\
\hline \multicolumn{2}{|l|}{ No. of visits completed by platform } \\
\hline Epic MyChart & $\begin{array}{l}894 \\
(78.5)\end{array}$ \\
\hline Zoom & $92(8.1)$ \\
\hline FaceTime & $90(7.9)$ \\
\hline Doximity & $43(3.8)$ \\
\hline VSee & $14(1.2)$ \\
\hline Doxy.me & $1(0.9)$ \\
\hline WhatsApp & $5(0.4)$ \\
\hline No. of visits requiring a switch to non-MyChart platform ${ }^{c}$ & $92(8.3)$ \\
\hline \multicolumn{2}{|l|}{ Reason for switch to non-MyChart platform ${ }^{d}$} \\
\hline Response not provided & $33(38.8)$ \\
\hline MyChart technical difficulties, not further specified & $25(29.4)$ \\
\hline Network connection failure & $14(16.5)$ \\
\hline Login to MyChart failed & $7(8.2)$ \\
\hline MyChart audio stopped transmitting & $5(5.9)$ \\
\hline Patient was unable to use MyChart app & $2(2.4)$ \\
\hline MyChart video froze & $1(1.2)$ \\
\hline Multiparty feature was needed & $1(1.2)$ \\
\hline Patient attempted to access MyChart on laptop & $1(1.2)$ \\
\hline Patient did not receive VSee invitation & $1(1.2)$ \\
\hline Patient mistakenly logged into MyChart & $1(1.2)$ \\
\hline Patient was unable to understand MyChart login instructions & $1(1.2)$ \\
\hline \multicolumn{2}{|l|}{ Non-MyChart platform used in case of switch ${ }^{d}$} \\
\hline Doximity & $23(27.0)$ \\
\hline FaceTime & $42(49.4)$ \\
\hline Telephone call & $3(3.5)$ \\
\hline VSee & $0(0.0)$ \\
\hline WhatsApp & $0(0.0)$ \\
\hline Zoom & $18(21.2)$ \\
\hline Response not provided & $6(7.0)$ \\
\hline
\end{tabular}

Abbreviation: $\mathrm{TN}$ = teleneurology.

All numbers are noted as frequency (\%), unless otherwise noted.

All clinician experience data are provided from April 13, 2020, to May 15, 2020.

All Likert scale ranges are 1 (very poor/unlikely) to 5 (very good/likely).

a Denominator for audio/video rating is 230, due to 121 (34.5\%) missing responses.

b Denominator for likelihood of recommending TN is 182 , due to $169(48.1 \%)$

missing responses.

${ }^{\mathrm{C}}$ Denominator is 1,110 visits, due to $29(2.5 \%)$ missing responses.

d Denominator is 85 visits, due to $7(7.6 \%)$ missing responses. patient experiences could have been influenced by the diagnoses of patients who were evaluated by TN. However, because our experience data were anonymous and not linkable to any patient information, we could not measure and compare scores across patient diagnoses. We note that most patients who were evaluated by TN during the pandemic had stable, nonurgent clinical problems, whereas in-person visits were reserved for urgent neurologic evaluation with the objective of avoiding a visit to the ED.

Furthermore, we found that many asynchronous TN services, with the exclusion of e-consults, were not used in the immediate COVID response. The latter finding is most likely related to the recent introduction of remote monitoring and digital evaluation and management services in 2019 and 2020, respectively. ${ }^{4,21,22}$ Although both asynchronous and synchronous TN services offer important advantages in the COVID-19 response by limiting patient and clinician exposure to the novel coronavirus, our findings are most likely secondary to the Department of Neurology's proactive approach to responding to the COVID-19 pandemic by primarily converting scheduled in-person visits to telephone or synchronous TN visits and the deployment of a majority of referring clinicians from the Department of Medicine to COVID teams during this period. In addition, the Centers for Medicare and Medicaid Services, which administers the US Medicare program and jointly administers Medicaid alongside individual US States, increased payments for telephone visits during the pandemic, and our Department also used prolonged non-face-to-face services by telephone to provide services during this time.

During the pandemic, faculty from all adult subspecialties (excluding stroke and neuro-oncology, which separately covered their separate inpatient and outpatient subspecialty services) were called to inpatient COVID medicine team service. While in theory, COVID-related redeployment of neurology clinicians could have affected the different types of patients that were evaluated by TN during our reported implementation, in practice, a coverage system was purposefully created for each subspecialty having deployed faculty so that outpatients in each subspecialty practice had one or more covering faculty members (not deployed to COVID service) to care for those subspecialty patients' clinical needs during the pandemic surge.

From our formative evaluation, we identified that state telehealth laws and reimbursement policies constituted a significant outer setting barrier to $\mathrm{TN}$ implementation during the prepandemic period. Many policy changes at the outset of the COVID-19 pandemic effectively addressed such barriers. For example, from March 13, 2020, onward, 51 of 55 US States and Territories issued proclamations outlining modifications to licensure requirements in response to COVID-19, which allowed health care professionals to practice TN more freely across state lines. ${ }^{3}$ Specifically, Connecticut, New Jersey, Pennsylvania, and Massachusetts offered waivers or temporary licenses for providers whose patients who were no longer located in New York State. 
Table 5 Platforms Used in the TN Response to COVID-19

\begin{tabular}{|c|c|c|c|c|c|c|}
\hline & MyChart & FaceTime & Doximity & WhatsApp & VSee & Zoom \\
\hline HIPAA compliant & Yes & No & Yes & No & Yes & Yes \\
\hline $\begin{array}{l}\text { Patient application } \\
\text { requirements }\end{array}$ & Yes & No & No & Yes & Yes & $\begin{array}{l}\text { Yes (mobile device } \\
\text { only) }\end{array}$ \\
\hline $\begin{array}{l}\text { Patient device } \\
\text { requirements }\end{array}$ & $\begin{array}{l}\text { Mobile device and } \\
\text { computer }^{a}\end{array}$ & $\begin{array}{l}\text { iPhone, iPad, and Mac } \\
\text { computer }\end{array}$ & Telephone only & $\begin{array}{l}\text { Smartphone } \\
\text { only }\end{array}$ & $\begin{array}{l}\text { Mobile device and } \\
\text { computer }\end{array}$ & $\begin{array}{l}\text { Mobile device and } \\
\text { computer }\end{array}$ \\
\hline $\begin{array}{l}\text { Clinician device } \\
\text { requirements }\end{array}$ & iOS mobile device & $\begin{array}{l}\text { iOS device and iOS } \\
\text { computer }\end{array}$ & iPhone only & $\begin{array}{l}\text { Mobile } \\
\text { device }\end{array}$ & $\begin{array}{l}\text { Mobile device and } \\
\text { computer }\end{array}$ & $\begin{array}{l}\text { Mobile device and } \\
\text { computer }\end{array}$ \\
\hline Cost & Free & Free & Free & Free & Free & $\$ 12 /$ month \\
\hline $\begin{array}{l}\text { Clinician application } \\
\text { requirements }\end{array}$ & Yes (Canto/Haiku) & $\mathrm{No}^{\mathrm{b}}$ & $\begin{array}{l}\text { Yes (Doximity } \\
\text { Dialer) }\end{array}$ & $\begin{array}{l}\text { Yes } \\
\text { (WhatsApp) }\end{array}$ & $\begin{array}{l}\text { Yes (VSee } \\
\text { Messenger) }\end{array}$ & Yes (Zoom) \\
\hline $\begin{array}{l}\text { Operating system } \\
\text { requirements }\end{array}$ & $\begin{array}{l}\text { Patients: any; } \\
\text { clinicians: iOS }\end{array}$ & iOS only & $\begin{array}{l}\text { Patients: any; } \\
\text { clinicians: iOS }\end{array}$ & Any & Any & Any \\
\hline
\end{tabular}

a MyChart desktop installation was not recommended for patients due to requirements for client software installation on patients' devices and frequent, manual security patch installation by hospital information technology staff.

${ }^{b}$ FaceTime is native to iOS.

Policy reforms also authorized the use of non-HIPAAcompliant platforms and loosened restrictions for Medicare beneficiaries receiving telehealth, allowing the distant site to be the patient's home.

Judging by the high acceptability of TN that we observed among patients, we anticipate that many patients will continue to opt for TN visits over in-person care as the COVID19 crisis subsides and that providers will apply for full licenses in neighboring states to practice $\mathrm{TN}$ to meet this demand. However, it remains unclear to what extent any of these policy shifts will remain in place and potentially affect the sustained adoption of $\mathrm{TN}$ as the global pandemic ends.

Despite the lifting of telemedicine reimbursement restrictions for Medicare-insured patients during the pandemic, our analysis found no significant difference in patient payor mix between periods. Medicare patients who were not covered for telemedicine prepandemic were offered the option to pay out of pocket for their TN care. The majority of these patients opted to pay out of pocket, which likely explains our finding that $20 \%$ of TN patients prepandemic were Medicare insured. However, our findings are expected, considering that payment reforms such as waiving of copayments and removal of restrictions were implemented for commercial insurance carriers as well as Medicare and Medicaid.

A significant implementation barrier was the limited nature of the remote neurologic examination, which we addressed through dissemination of educational material (table e-2, links.lww.com/ $\mathrm{CPJ} / \mathrm{A} 264$ ) and ongoing education sessions to clinicians. Despite these solutions, some elements such as the fundoscopic, sensory, and detailed motor examinations remain difficult to perform remotely without a qualified telepresenter. These limitations are ripe for digital health and remote monitoring device innovations to address, as well as research to study what aspects of the in-person examination are needed for clinical decision making vs solely to meet documentation requirements. ${ }^{4,14}$

For instance, digital health solutions that adapt an ophthalmoscope to a mobile device camera to perform fundoscopy and remotely transmit fundus images, ${ }^{23}$ as well as a mobile device application that tests visual acuity ${ }^{24}$ could supplement the existing TN examination. ${ }^{14}$ Finally, a remote patent monitoring solution such as automated video analysis software to detect and quantify bradykinesia and tremor in Parkinson disease from patient videos ${ }^{25}$ could potentially overcome the relatively nongranular video resolution of standard TN video encounters and thereby improve an examiner's assessment of a patient's fine motor examination.

Our results also demonstrate that the postpandemic period was associated with a tripling of $\mathrm{TN}$ platforms. The platforms included multiple non-HIPAA-compliant (e.g., Apple FaceTime $^{\mathrm{TM}}$ and WhatsApp Messenger ${ }^{\mathrm{TM}}$ ) as well as HIPAAcompliant solutions (e.g., Doximity ${ }^{\oplus}$ and $\mathrm{Zoom}^{\odot}{ }^{\text {) }}$ comprising a variety of implementation characteristics and requirements for patients and clinicians (table 5). Although faculty were guided to use the institution's official MyChart platform whenever possible, they were also given free choice of platform to use for $\mathrm{TN}$, which most directly explains the numerical increase in TN platforms.

More specifically, the use of several non-HIPAA-compliant platforms is consistent with the Office of Civil Rights' announcement of HIPAA compliance enforcement discretion in late March 2020. Among HIPAA-compliant platforms, the use of VSee, Zoom, and Doximity during the pandemic response is likely explained by several practical factors. VSee had been used for TN before the pandemic and remained 
favored by a small number of providers. Clinicians began to use Doximity for its video call functionality, which was discovered incidentally as clinicians searched for solutions to avoid disclosing their mobile phone numbers when contacting patients via telephone during the pandemic. Finally, most clinical faculty were already using Zoom for administrative videoconferencing by the time the COVID-19 pandemic response began, which made Zoom a straightforward alternative to the official MyChart platform.

In addition, Zoom was probably the most commonly used non-MyChart platform due to functionality that addressed adaptability barriers we identified during the formative evaluation of our TN implementation (table e-1, links.lww.com/ CPJ/A263), including screen sharing, third-party conferencing, and desktop deployment through a hyperlink rather than mobile device application. Despite these advantages, in cases where clinicians required to switch from MyChart, FaceTime was the most commonly used non-MyChart platform. The most likely explanation for this finding is that the MyChart TN capability was only available to clinicians on iOS devices, such as the iPhone or the iPad, which have FaceTime as a built-in application (table 5). Alternatively, this finding may be due to the leading position occupied by iOS platforms in the US mobile device market, ${ }^{26}$ or that FaceTime video calls can be made more easily than with Zoom, which requires creating a meeting and sending a Web link to the patient.

Our study was limited by several factors. First, we did not assess the reasons for which patients or providers chose to use TN over telephone visits or deferral of care and therefore could not ascertain and differentiate how much of the increase in TN volume was attributable to patient choice or departmental dissemination efforts. Moreover, we excluded telephone visits from our definition of $\mathrm{TN}$, which may have allowed a better understanding of factors associated with TN utilization. Second, we relied on anonymous survey information for patient and clinician experience, which may have introduced response bias and limited our ability to adjust our results for multiple responses provided by the same respondents. We also were not able to ascertain the platforms used by patients responding to the survey. Third, the pandemic period in our study was restricted to 2 months, which limited our ability to understand the long-term adoption and effects of TN at our institution, particularly with the potential elimination of emergency policies, such as shelter-in-place orders and suspension of HIPAA enforcement. Fourth, we lacked clinician and patient experience data for the entire 2-month pandemic period, and a substantial proportion of our faculty were deployed to COVID service during this period and unable to engage in $\mathrm{TN}$, although covered by their colleagues. Finally, the clinician-facing surveys we used only assessed clinicians' experience with technology, rather than specific aspects of their clinical practice in $\mathrm{TN}$, such as clinical decision making or diagnostic accuracy.

In addition, we did not include visit data from hospital-based clinics, which are not operated directly by the Department

\section{TAKE-HOME POINTS}

$\rightarrow$ At a tertiary care center in New York City, the first 2 months of the coronavirus respiratory disease 2019 pandemic was associated with a significant expansion in teleneurology (TN) utilization, as well as an increase in the number of technology platforms used to conduct TN.

$\rightarrow$ Proactive application of a formal implementation science framework facilitated rapid and effective TN expansion.

$\rightarrow$ Lifting of Medicare reimbursement restrictions as well as active education and outreach efforts were key strategies that enabled effective implementation.

$\rightarrow$ Patients receiving TN generally reported a positive experience with TN. By contrast, providers' experience was initially less favorable, although it improved later in the implementation.

and have a higher proportion of patients with Medicaid insurance than faculty practices. Our results on patient perspectives and barriers may therefore not reflect those of the subpopulation with significant socioeconomic barriers to technology, including Wi-Fi, broadband internet access, and smartphones. These data may have generated valuable and translatable insights to other institutions contemplating similar implementations and platforms to ours.

This analysis of an academic neurology department's response to the COVID-19 public health crisis illustrates significant expansion in utilization and technology platform usage associated with the pandemic. Patients reported high acceptability, whereas clinicians found $\mathrm{TN}$ to be relatively less acceptable due to technological challenges. Subsequent studies should investigate the optimal strategy for implementation, as well as the clinician, patient, and health system effects of TN use. Further studies should also investigate the relationships between $\mathrm{TN}$ utilization, socioeconomic factors, and technological literacy.

\section{Study Funding}

No targeted funding reported.

\section{Disclosure}

B. Kummer holds stock options in NeuroView LLC and serves on its advisory board, as well as serving as consultant to MD Aware LLC. C. Sweetnam, G. Naasan, B.G. Vickrey, D. Harvey, and K. Gallagher report no disclosures relevant to the manuscript; N. Jetté receives grant funding paid to her institution for grants unrelated to this work from the NINDS (NIH U24NS107201 and NIH IU54NS100064) and PCORI. She is the Bludhorn Professor of International Medicine at the Icahn 
School of Medicine at Mount Sinai. She receives an honorarium for her work as an Associate Editor of Epilepsia. She is a member of the editorial board of JAMA Neurology. Full disclosure form information provided by the authors is available with the full text of this article at Neurology.org/cp.

\section{Publication History}

Received by Neurology: Clinical Practice July 28, 2020. Accepted in final form January 19, 2021.

\section{Appendix Authors}

\begin{tabular}{|c|c|c|}
\hline Name & Location & Contribution \\
\hline $\begin{array}{l}\text { Benjamin R. } \\
\text { Kummer, MD }\end{array}$ & $\begin{array}{l}\text { Department of Neurology, } \\
\text { Icahn School of Medicine at } \\
\text { Mount Sinai and Clinical } \\
\text { Informatics, Mount Sinai } \\
\text { Health System, New York }\end{array}$ & $\begin{array}{l}\text { Designed and } \\
\text { conceptualized the study; } \\
\text { collected data; analyzed } \\
\text { data; drafted the } \\
\text { manuscript; and revised } \\
\text { the manuscript for key } \\
\text { intellectual content }\end{array}$ \\
\hline $\begin{array}{l}\text { Chloe } \\
\text { Sweetnam, MSc }\end{array}$ & $\begin{array}{l}\text { Department of Neurology, } \\
\text { Icahn School of Medicine at } \\
\text { Mount Sinai, New York }\end{array}$ & $\begin{array}{l}\text { Collected and analyzed } \\
\text { data and revised the } \\
\text { manuscript for key } \\
\text { intellectual content }\end{array}$ \\
\hline
\end{tabular}

\begin{tabular}{lll}
\hline $\begin{array}{l}\text { Barbara } \\
\text { Vickrey, MD, } \\
\text { MPH }\end{array}$ & $\begin{array}{l}\text { Department of Neurology, } \\
\text { Icahn School of Medicine at } \\
\text { Mount Sinai, New York }\end{array}$ & $\begin{array}{l}\text { Designed and } \\
\text { conceptualized the study } \\
\text { and revised the manuscript } \\
\text { for key intellectual content }\end{array}$ \\
\hline $\begin{array}{l}\text { Georges } \\
\text { Naasan, MD }\end{array}$ & $\begin{array}{l}\text { Department of Neurology, } \\
\text { Icahn School of Medicine at } \\
\text { Mount Sinai, New York }\end{array}$ & $\begin{array}{l}\text { Designed and } \\
\text { conceptualized the study } \\
\text { and revised the manuscript } \\
\text { for key intellectual content }\end{array}$ \\
& &
\end{tabular}

Dayneen Department of Neurology, Collected data and revised Harvey, CPC Icahn School of Medicine at the manuscript for key Mount Sinai, New York intellectual content

\begin{tabular}{lll}
\hline Kimberly & Department of Neurology, & Collected data and revised \\
Gallagher & Icahn School of Medicine at & the manuscript for key \\
& Mount Sinai, New York & intellectual content
\end{tabular}

Nathalie Jetté, Departments of Neurology Designed and MD, MSc and Population Health conceptualized the study Science and Policy, Icahn and revised the manuscript School of Medicine at Mount Sinai, New York

4. Klein BC, Busis NA. COVID-19 is catalyzing the adoption of teleneurology. Neurology 2020;94:903-904.

5. Wechsler LR, Demaerschalk BM, Schwamm LH, et al. Telemedicine quality and outcomes in stroke: a scientific statement for healthcare professionals from the American Heart Association/American Stroke Association. Stroke 2017;48:e3-e25.

6. Dorsey ER, Glidden AM, Holloway MR, Birbeck GL, Schwamm LH. Teleneurology and mobile technologies: the future of neurological care. Nat Rev Neurol 2018;14:285-297.

7. Hatcher-Martin JM, Adams JL, Anderson ER, et al. Telemedicine in neurology: telemedicine work group of the American Academy of Neurology update. Neurology 2020;94:30-38.

8. Kirby J, Stewart E. How New York became the epicenter of America's coronavirus crisis. Available at: vox.com/coronavirus-covid19/2020/3/27/21195162/new-yorkcoronavirus-news-andrew-cuomo-hospitals-population-ventilators. Accessed October $26,2020$.

9. Johns Hopkins University. COVID19 Map-Johns Hopkins Coronavirus Resource Center. Available at: coronavirus.jhu.edu/map.html. Accessed April 27, 2020.

10. Cuomo AM. Executive Order No 202.6, Continuing Temporary Suspension and Modification of Laws Relating to the Disaster Emergency. Available at: governor.ny. gov/news/no-2026-continuing-temporary-suspension-and-modification-laws-relating-disaster-emergency. Accessed June 29, 2020.

11. Mehrotra A, Chernew M, Linetsky D, Hatch H, Cutler D. The impact of the COVID-19 pandemic on outpatient cisits: practices are adapting to the new normal. The Commonwealth Fund. Available at: commonwealthfund.org/publications/ 2020/jun/impact-covid-19-pandemic-outpatient-visits-practices-adapting-new-normal. Accessed June 29, 2020.

12. Duffy CO, Boyle LM, Nichols BD. HHS Issues Section 1135 Waiver, and CMS Issues Blanket Waivers of Health Care Laws, in Response to Coronavirus (COVID-19) Emergency. The National Law Review. Available at: natlawreview.com/article/hhsissues-section-1135-waiver-and-cms-issues-blanket-waivers-health-care-laws. Accessed March 16, 2020.

13. Centers for Medicare and Medicaid Services (CMS). Press Release - President Trump Expands Telehealth Benefits for Medicare Beneficiaries during COVID-19 Outbreak. Available at: cms.gov/newsroom/press-releases/president-trump-expands-telehealth-benefits-medicare-beneficiaries-during-covid-19-outbreak. Accessed May 23, 2020.

14. Grossman SN, Han SC, Balcer LJ, et al. Rapid implementation of virtual neurology in response to the COVID-19 pandemic. Neurology 2020;94:1077-1087.

15. Trump DJ. Proclamation on Declaring a National Emergency Concerning the Novel Coronavirus Disease (COVID-19) Outbreak. Available at: whitehouse. gov/presidential-actions/proclamation-declaring-national-emergency-concerning-novel-coronavirus-disease-covid-19-outbreak/. Accessed April 28, 2020.

16. U.S. Department of Health \& Human Services. Notification of enforcement discretion for telehealth remote communications during the COVID-19 Nationwide public health emergency. Available at: hhs.gov/hipaa/for-professionals/special-topics/ emergency-preparedness/notification-enforcement-discretion-telehealth/index.html. Accessed April 28, 2020.

17. Likert R. A technique for the measurement of attitudes. Arch Psych $1932 ; 22: 55$

18. Stetler CB, Legro MW, Wallace CM, et al. The role of formative evaluation in implementation research and the QUERI experience. J Gen Intern Med 2006;21(suppl 2):S1-S8.

19. Damschroder LJ, Lowery JC. Evaluation of a large-scale weight management program using the consolidated framework for implementation research (CFIR). Implement Sci 2013;8:51.

20. Powell BJ, Waltz TJ, Chinman MJ, et al. A refined compilation of implementation strategies: results from the Expert Recommendations for Implementing Change (ERIC) project. Implement Sci 2015;10:21

21. Tornese N. Meet the New CPT Codes to Report E-Visits in 2020. Outsource Strategies International Blog. Available at: outsourcestrategies.com $/ \mathrm{blog} / \mathrm{meet}$-thenew-cpt-codes-to-report-e-visits-in-2020.html. Accessed June 19, 2020.

22. Centers for Medicare and Medicaid Services (CMS). 2019 Medicare Physician Fee Schedule 2018. Available at: federalregister.gov/d/2018-24170. Accessed June 19, 2020.

\section{References}

1. Demaerschalk BM, Berg J, Chong BW, et al. American telemedicine association: telestroke guidelines. Telemed J E Health 2017;23:376-389.

2. Centers for Medicare and Medicaid Services (CMS). Physicians and other clinicians: CMS flexibilities to fight COVID19. Available at: cms.gov/files/document/covid-19physicians-and-practitioners.pdf. Accessed June 17, 20

3. Federation of State Medical Boards. U.S. States and Territories modifying requirements for telehealth in response to COVID-19. Available at: fsmb.org/siteassets/ advocacy/pdf/states-waiving-licensure-requirements-for-telehealth-in-responseto-covid-19.pdf. Accessed June, 17, 2020.

23. Welch Allyn. iEXAMINER. Available at: welchallyn.com/en/microsites/iexaminer. html. Accessed October 19, 2020.

24. Dok LLC. Eye Chart Pro App. Available at: eyechartproapp.com/. Accessed October 19, 2020.

25. Machine Medicine Ltd. KELVIN-PD - machine medicine. Available at: machinemedicine.com/kelvin-pd/. Accessed November 11, 2020.

26. Statcounter. Mobile operating system market share - United States of America. Available at: gs.statcounter.com/os-market-share/mobile/united-states-of-america/. Accessed June 19, 2020. 


\section{Neurology ${ }^{\circ}$ Clinical Practice}

Teleneurology Expansion in Response to the COVID-19 Outbreak at a Tertiary Health System in New York City

Benjamin R. Kummer, Chloe Sweetnam, Barbara G. Vickrey, et al.

Neurol Clin Pract 2021;11;e102-e111 Published Online before print March 9, 2021

DOI 10.1212/CPJ.0000000000001057

This information is current as of March 9, 2021

Updated Information \&

Services

References

Subspecialty Collections

Permissions \& Licensing

Reprints including high resolution figures, can be found at:

http://cp.neurology.org/content/11/2/e102.full.html

This article cites 10 articles, 1 of which you can access for free at: http://cp.neurology.org/content/11/2/e102.full.html\#\#ref-list-1

This article, along with others on similar topics, appears in the following collection(s):

All Health Services Research

http://cp.neurology.org//cgi/collection/all_health_services_research COVID-19

http://cp.neurology.org//cgi/collection/covid_19

Information about reproducing this article in parts (figures,tables) or in its entirety can be found online at:

http://cp.neurology.org/misc/about.xhtml\#permissions

Information about ordering reprints can be found online:

http://cp.neurology.org/misc/addir.xhtml\#reprintsus

Neurol Clin Pract is an official journal of the American Academy of Neurology. Published continuously since 2011, it is now a bimonthly with 6 issues per year. Copyright ( 2021 American Academy of Neurology. All rights reserved. Print ISSN: 2163-0402. Online ISSN: 2163-0933.

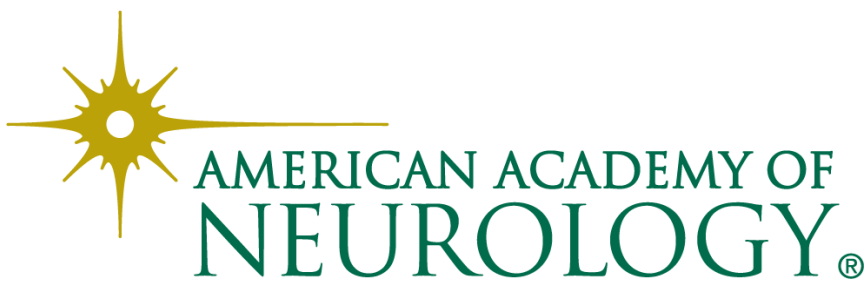

